\title{
Which Firms are Left in the Periphery? - Spatial Sorting of Heterogeneous Firms with Scale Economies in Transportation*
}

\author{
Rikard Forslid $^{\dagger} \quad$ Toshihiro Okubo
}

February 2013

\begin{abstract}
This paper introduces scale economies or density economies in transportation in a trade and geography model with heterogeneous firms. This relatively small change to the standard model produces a new pattern of spatial sorting among firms. Contrary to the existing literature, our model produces the result that firms of intermediate productivity relocate to the large core region, whereas high and low productivity firms remain in the periphery. Trade liberalisation leads to a gradual relocation to the core, with the most productive firms remaining in the periphery.
\end{abstract}

\section{JEL Classification: F12, F15}

Keywords: heterogeneous firms, transportation costs, scale economies

\footnotetext{
*Financial support from the The Swedish Research Council and The Handelsbanken Research Foundation is gratefully acknowledged by Forslid.

${ }^{\dagger}$ Stockholm University and CEPR; email: rf@ne.su.se.

${ }^{\ddagger}$ Kobe University; email: okubo@rieb.kobe-u.ac.jp.
} 


\section{Introduction}

This paper introduces scale economies or density economies in transportation in a trade and geography model with heterogeneous firms. It is shown how density economies in transportation dramatically change the location pattern of firms.

Baldwin and Okubo (2006) show how the most productive firms tend to agglomerate in the large central region, when heterogeneous firms are added to a trade and geography framework. ${ }^{1}$ Thus, their model produces a spatial sorting pattern with the most productive firms in the centre and the least productive firms in the periphery. The sorting pattern is amplified by trade liberalisation. Lower trade costs induce more firms to relocate to the central region, and it is always the most productive firm in the periphery that has the strongest incentive to relocate towards the centre. The result by Baldwin and Okubo (2006) underscores the concerns that small regions or countries could end up as losers when economic integration leads to an agglomeration of firms to large central regions. Not only does the periphery lose industry in general, it is the most productive firms that leave.

Our paper shows how scale economies in transportation can overturn the result by Baldwin and Okubo (2006). The generic case in our model is that firms of intermediate productivity have the strongest incentives to agglomerate to the larger region, and it is even the case that the least productive firms relocate to the core for strong enough scale economies in transportation. Thus, our model produces the opposite spatial sorting pattern as compared to Baldwin and Okubo. The reason for our result is that transportation costs become relatively less important for the large and most productive firms in our model, since they obtain low freight rates because of their large shipments.

Trade liberalisation accentuates the spatial sorting pattern, and the last firm to leave the periphery is the most productive one. Our results imply that different degrees of scale economies among industrial sectors lead to different spatial sorting patterns among the sectors. This is a qualification for the well-known result from the trade and geography literature that different sectorial levels of trade costs will lead to different degrees of agglomeration among sectors.

The trade and economic geography literature (see e.g. Fujita et al. 1999, Baldwin et al. 2003, Fujita and Thisse, 2002) treats trade costs as a constant parameter, which may be proportional to geographical distance or other. However, as pointed out by McCann (2005), this is at odds with wide-ranging empirical work on transport rate structures in regional economics which almost universally has found economies of distance and scale in transportation.

There are a few trade and geography papers that model transport costs in an explicit manner. Behrens et al. (2006) introduce density economies in transportation in a trade and geography model. They show how this may give rise to multiple equilibria and a catastrophic agglomeration of industry. Behrens and Picard (2011) study the location choice of firms when

\footnotetext{
${ }^{1}$ Similar results are found by Okubo et al. (2010) using the linear model of Ottaviano et al. (2002) and by Saito et al. (2010) and Forslid and Okubo (2012) using a three-country model. Also the vertical linkage model produces similar results (Okubo 2009).
} 
transportation costs are endogenous. They show how the back-haul problem increases the freight rates on exports from the central country, and that this dampens the tendencies for agglomeration. However, none of these papers analyse spatial sorting of firms, as they work with models with homogenous firms.

\subsection{Scale economies in transportation}

We will here relate firms' varying production volumes to differences in transportation costs. It is quite natural that freight rates per unit decline with the size of a shipment due to scale economies in transportation. Scale economies in transportation are well established in regional economics (see e.g. McCann 2005) and e.g. Hummels and Skiba (2004) find that a 10 percent increase in product weight/value leads to a 4-6 percent increase in shipping costs using U.S. data. $^{2}$ However, almost all types of transportation such as trucks, airfreight and ships have freight rates that are declining in the volume transported.

It is also the case that the transportation costs remain substantial in spite of the globalization process during the last decades. In fact, the tramp freight rates have roughly remained constant since the 1950's, while the airfreight rates have fallen (Hummels 2007), and Anderson and van Wincoop (2004) find that the total trade costs in high income countries amount to an ad valorem tax equivalent to $170 \%$.

\section{Model}

Here, we introduce scale economies in transportation in the Baldwin and Okubo (2006) model. This model is based on the Melitz (2003) heterogeneous firms model combined with the 'footloose capital' new economic geography model by Martin and Rogers (1995). Our model involves firm heterogeneity in transport costs as well as in labour productivity. In essence, productive firms export more and their trade costs per unit are therefore lower than those of less productive firms due to scale economies in transportation.

\section{$2.1 \quad$ Basics}

There are two regions with an asymmetric population (market size). Region $j$ is the larger core region and Region $k$ is a smaller region. There are two types of factors of production, capital and labour, and each country has the same proportion of capital to labour. That is, regions are identical except for size and region $j$ has a share $s_{j}$ of both factors of production. Capital, which is sector specific, can move between regions but capital owners do not. Labour can move freely between sectors but are immobile between regions. A homogeneous good is produced with a constant-returns technology only using labour. Differentiated manufactures are produced with increasing-returns technologies using both capital and labour.

\footnotetext{
${ }^{2}$ Another example is Mori and Nishikimi (2002) who find that the cost of transportation by ship declines by $0.31 \%$ when the shipping volume increases by $1 \%$.
} 
All individuals have the utility function

$$
U=C_{M}^{\mu} C_{A}^{1-\mu}, \quad \text { where } C_{M}=\left[\int_{l \in \Psi} c_{l}^{(\sigma-1) / \sigma} d l\right]^{\sigma /(\sigma-1)}
$$

where $\mu \in(0,1), \sigma>1$ are constants, and $\Psi$ is the set of consumed variety. $C_{M}$ is a consumption index of manufacturing goods and $C_{A}$ is consumption of the homogeneous good. $c_{l}$ is the amount consumed of variety $l$. Region subscripts are suppressed when possible for ease of notation.

Each consumer spends a share $\mu$ of his income on manufactures. The total demand for a domestically produced variety $i$ is

$$
x_{i}=\frac{p_{i}^{-\sigma}}{\int_{l \in \Psi} p_{l}^{1-\sigma} d l} \cdot \mu Y
$$

where $p_{l}$ is the price of variety $l$ and $Y$ is income in the region.

Ownership of capital is assumed to be fully regionally diversified; that is, if one region owns $X$-percent of the world capital stock, it will own $X$-percent of the capital in each region. Therefore, the income of each region is constant and independent of the location of capital. Total expenditure equals total factor income. Firms' fixed factor of production is capital and the variable factor is labour. The return to capital therefore equals firms' operating profit in equilibrium. Thus, the total equilibrium expenditures can be written $E=w L+r K=$ $w L+\mu E / \sigma$. Without loss of generality, we choose units so that $L \equiv 1$, which gives $E=\frac{1}{1-\mu / \sigma}$. The income of region $j$ is equal to its share of total expenditures given by

$$
Y_{j}=s_{j} E=s_{j} \frac{\sigma}{\sigma-\mu} .
$$

$Y_{j}$ is thus constant irrespective of the location of capital; i.e. also out of long-run equilibrium.

Turning to the supply side, the homogeneous good sector is a constant returns and perfect competition sector. The unit factor requirement of the homogeneous good is one unit of labour. The good is freely traded and since it is also chosen as the numeraire, we have

$$
p_{A}=w=1,
$$

where $w$ is the wage of workers in all regions.

In the production of differentiated goods, firms have a firm-specific unit labour input coefficient $(a)$ and uses one unit of capital, as in the standard footloose capital model. There is a fixed world capital endowment, implying that the world mass of firms, $N^{W}$, is constant, whilst international capital mobility allows firms to move between regions. We normalise the world mass of differentiated firms to one, $N^{W} \equiv 1$. The total costs for firm $i$ are specified as

$$
T C_{i}=\pi_{i}+a_{i} x_{i}
$$


where $\pi$ is return to capital. The variable cost consists of labour. Importantly, firms are heterogeneous and their firm-specific marginal production costs $a_{i}$ are distributed according to the cumulative distribution function $G(a)$.

Geographical distance is represented by trade costs. Shipping the manufactured good involves a frictional trade cost of the "iceberg" form: for one unit of good from region $j$ to arrive in region $k, \tau_{j k}>1$ units must be shipped. The trade costs are symmetric between regions $\tau_{j k}=\tau \forall j, k$.

Profit maximisation by manufacturing firms leads to a constant mark-up over marginal cost

$$
p_{i}=\frac{\sigma}{\sigma-1} a_{i}
$$

and the export price is $p_{i} \tau_{i}$.

We assume that there are scale economies in transportation, implying that the freight rate falls with the quantity shipped. Firms are heterogeneous in labour productivity, $a$, and productive firms produce more and export more. Productive firms therefore have lower freight rates. To preserve the analytical tractability of the model, we assume the following simple relationship between transport costs and $a$ :

$$
\tau_{i}=t a_{i}^{\gamma},
$$

where $t \geqslant 1$ and $\gamma \geqslant 0$ are parameters. $t$ represents the fundamental level of the iceberg trade cost, whereas $\gamma$ is the degree of scale economies of transportation. A larger $\gamma$ implies larger scale economies. We assume that $\gamma>0$, implying that $\frac{d \tau_{i}}{d a_{i}}>0$. Note that our specification generates the standard case of a constant trade cost $\left(\tau_{i}=t\right)$ when $\gamma=0$.

Firm heterogeneity in labour requirements, $a_{i}$, is probabilistically allocated among firms. To analytically solve the model, we follow Forslid and Okubo (2012) and assume the following cumulative density function of $a$ :

$$
G(a)=\frac{a^{\rho}-\underline{a}^{\rho}}{a_{0}^{\rho}-\underline{a}^{\rho}}
$$

where $\rho$ is a shape parameter and $a_{0}$ is a scaling factor. We assume the distribution to be truncated at $\underline{a}$, which is exogenously given, meaning that $\underline{a} \leq a \leq a_{0}$. This implies that the productivity of firms is bounded. Without loss of generality, we can normalise $a_{0} \equiv 1$. For convenience, the lower bound for the marginal cost is specified as $\underline{a} \equiv t^{-\frac{1}{\gamma}}$, which implies that $\tau_{i}=1$ when $a=\underline{a} .^{3}$

\subsection{Short-run equilibrium}

In the short-run equilibrium, the allocation of capital in each region is taken to be fixed. $s_{j}$ denotes the share of capital and the number (mass) of firms in region $j$ since one unit of capital corresponds to one firm.

\footnotetext{
${ }^{3}$ The assumption that the most productive firm has zero trade costs is convenient when solving the model, and it rules out negative trade costs.
} 
The return to capital of a firm in region $j$ is the firm's operating profit,

$$
\pi_{j}\left(a_{i}\right)=\frac{a_{i}^{1-\sigma}}{(\sigma-\mu)} \mu\left(\frac{s_{j}}{\bar{\Delta}_{j}}+\phi_{i} \frac{1-s_{j}}{\bar{\Delta}_{k}}\right),
$$

where $\phi_{i} \equiv \tau_{i}^{1-\sigma}$, the right-hand side follows from the demand functions in (2), and

$$
\overline{\Delta_{j}} \equiv s_{j} \int_{\underline{a}}^{1} a_{i}^{1-\sigma} d G(a)+\left(1-s_{j}\right) \int_{\underline{a}}^{1} \phi_{i} a_{i}^{1-\sigma} d G(a) .
$$

The object $\phi_{i}$, ranging between 0 and 1 , stands for firm $i$ "free-ness" of trade between region $j$ and $k$ ( 0 is autarky and 1 is zero trade costs). It is assumed that the labour stock is sufficiently large so that the homogenous sector, which pins down the wage, is active in all regions.

Furthermore, using (7) and defining $\varphi \equiv t^{1-\sigma} \in[0,1]$ gives, $\phi_{i}=\tau_{i}^{1-\sigma}=\varphi a_{i}^{\gamma(1-\sigma)}$, where $a_{i}^{\gamma(1-\sigma)}$ is a firm-specific component and $\varphi$ is a measure of the overall degree of trade freeness.

Consider now what would happen if firms were allowed to move between regions. Firms choose location in their search of the highest capital returns. Using (9), a firm will move from Region $j$ to $k$ when

$$
\pi_{j}\left(a_{i}\right)-\pi_{k}\left(a_{i}\right)-\chi=\frac{a_{i}^{1-\sigma}}{(\sigma-\mu)}\left(1-\phi_{i}\right) \mu\left(\frac{s_{j}}{\bar{\Delta}_{j}}-\frac{1-s_{j}}{\bar{\Delta}_{k}}\right)-\chi>0,
$$

where $\chi$ is a per-unit of capital fixed relocation cost and trade costs are assumed to be symmetric, $\tau_{j k}=\tau_{k j}$.

\subsection{Relocation tendencies}

Before moving to the full long-run equilibrium of the model, we consider the relocation incentives faced by firms starting out from the initial equilibrium. Using (7), the profit differential is given by

$$
\pi_{j}\left(a_{i}\right)-\pi_{k}\left(a_{i}\right)-\chi=\frac{\mu}{(\sigma-\mu)}\left(1-\varphi a_{i}^{\gamma(1-\sigma)}\right) a_{i}^{1-\sigma}\left(\frac{s_{j}}{\bar{\Delta}_{j}}-\frac{1-s_{j}}{\bar{\Delta}_{k}}\right)-\chi
$$

Differentiating the profit gap function in terms of $a$ gives:

$$
\frac{d\left(\pi\left(a_{i}\right)-\pi\left(a_{i}\right)\right)}{d a}=-\left(1-\varphi(1+\gamma) a_{i}^{\gamma(1-\sigma)}\right) a_{i}^{-\sigma} \frac{\mu(\sigma-1)}{(\sigma-\mu)}\left(\frac{s_{j}}{\bar{\Delta}_{j}}-\frac{1-s_{j}}{\bar{\Delta}_{k}}\right) .
$$

From this expression, it appears that the incentives of firms depend on the level of scale economies in transportation, $\gamma$. With no scale economies, $\gamma=0$, we have returned to the Baldwin and Okubo (2006) case as depicted in Figure 1. Only the most productive firms (the low $a$ firms) will have incentives to relocate in this case. The most productive firms are better equipped to handle the strong competition in the large market, and only these firms will expand the sales and increase the profits sufficiently to overcome the relocation cost. $\gamma=0$ therefore tends to lead to spatial sorting with the most productive firms sorting to the larger market.

The relocation tendencies are very different when there are scale economies in transportation, $\gamma>0$. High scale economies and not too low trade costs $\left(\gamma>\frac{1}{\varphi}-1\right)$ will lead to the opposite case 


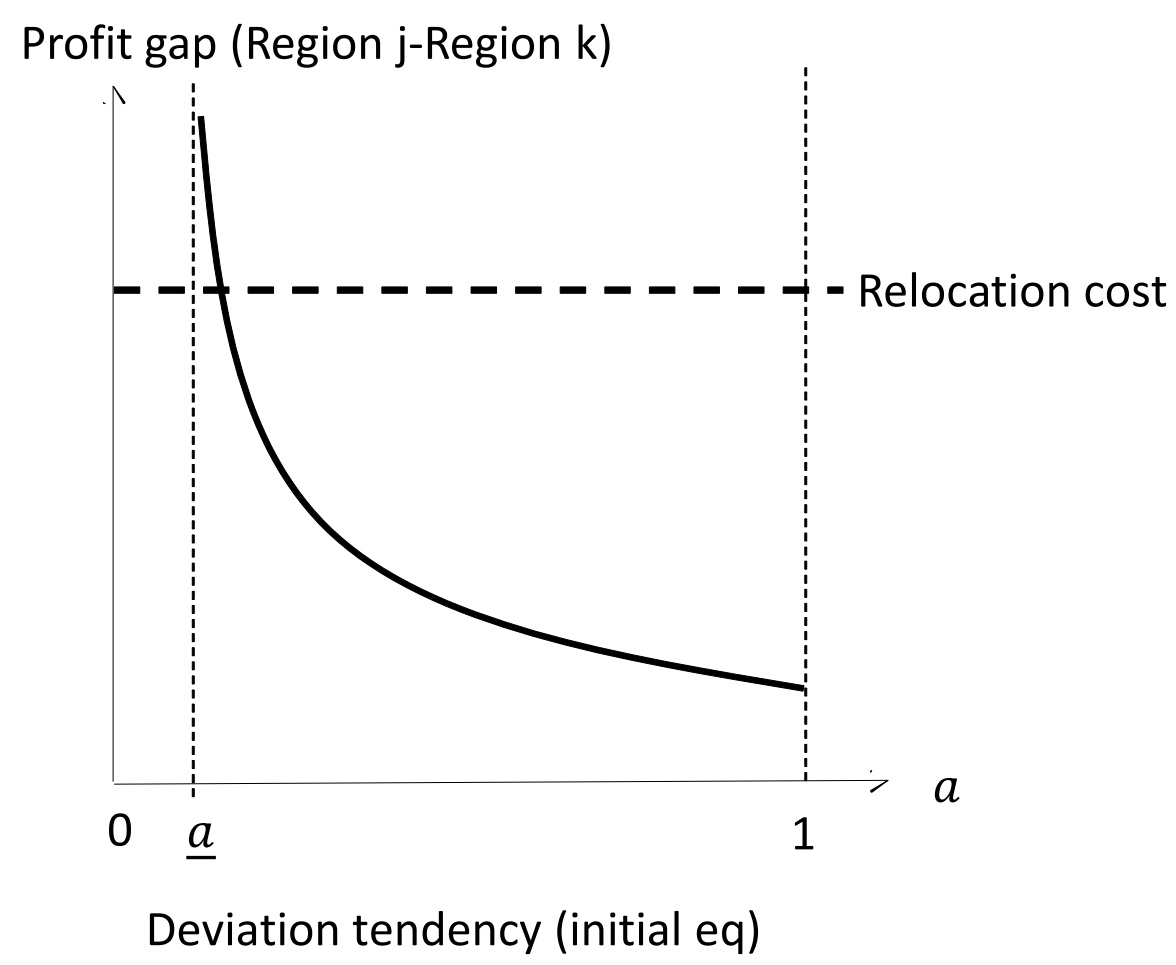

Figure 1: No scale economies in transportation.

of a positively sloping profit differential curve as seen from (13). Figure 2 illustrates this case. Here, it is the least productive firms that have the strongest incentives to relocate to the larger region. High-productivity firms enjoy low transportation costs, and location therefore becomes relatively unimportant for them. Low-productivity firms, in contrast, face high transportation costs, and therefore they have large gains from moving. Thus, this case tends to lead to spatial sorting with high-productivity firms in the periphery.

Finally, the generic case, when scale economies in transportation are not too large, is a hump-shaped profit differential curve as shown in Figure 3. The exact conditions for this case are stated in the following proposition:

Proposition 1 The firms of intermediate productivity have the strongest incentives to start relocating to the large region if the conditions $\gamma<\frac{1}{\varphi}-1$, and $\gamma>0$ hold.

Proof: First, when $a=\underline{a} \equiv t^{-\frac{1}{\gamma}}, \frac{d\left(\pi\left(a_{i}\right)-\pi\left(a_{i}\right)\right)}{d a}>0$ always holds from (13). On the other hand, from (13), when $a=1, \gamma>0$, and $\gamma<\frac{1}{\varphi}-1, \frac{d\left(\pi\left(a_{i}\right)-\pi\left(a_{i}\right)\right)}{d a}<0$. This implies that the profit gap curve, $\pi\left(a_{i}\right)-\pi\left(a_{i}\right)$, must be hump-shaped.

We will assume that the sufficient conditions in Proposition 1 hold in the following. Intuitively, the least productive firms have difficulties surviving in the large region, while the most productive firms have such low transportation costs that they do not find it profitable to pay the relocation cost in order to move to the core. Therefore, it is the firms with intermediate productivity that have the strongest incentives to move from the periphery to the core. This 


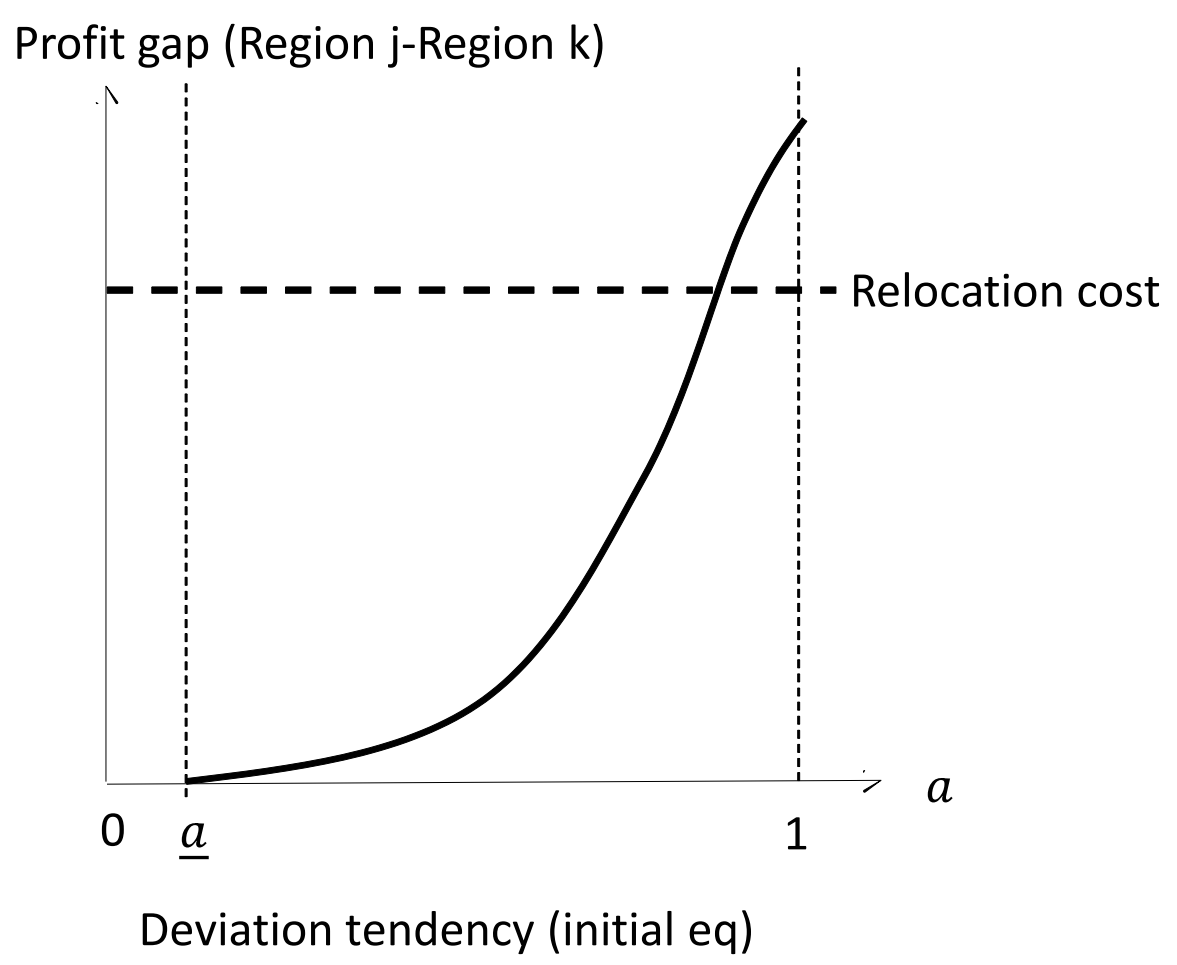

Figure 2: High scale economies in transportation

relocation tendency stands in sharp contrast to Baldwin and Okubo (2006) and other studies in this vein, where the most productive firms always have the largest incentive for relocation and are the first movers to the large market.

Having analysed the relocation tendencies starting from a short-run equilibrium where capital is fixed, we now turn to the long-run equilibrium after firms and capital have relocated.

\section{The Long-run Equilibrium}

Capital is fully mobile between regions in the long run. To simplify the analysis, we assume that there is a firm (capital) relocation cost à la Baldwin and Okubo (2006) that is related to the migration pressure. More specifically, we assume the cost of moving to be given by:

$$
\chi=\kappa\left(\frac{d F\left(a_{U}\right)}{d t}-\frac{d F\left(a_{L}\right)}{d t}\right)
$$

where $\kappa$ is a constant, and $a_{U}$ and $a_{L}$ are the two cut-off productivities for the hump-shaped profit differential curve (see Figure 3). The relocation cost is high when many firms move at the same time, but gradually declines to zero as the migration pressure falls as we approach the equilibrium. The firm with the most to gain from relocating has the highest willingness to pay the cost for relocation. As a consequence, firms relocate in order of productivity. The relocation process is illustrated by Figure 4 . 


\section{Profit gap (Region j-Region k)}

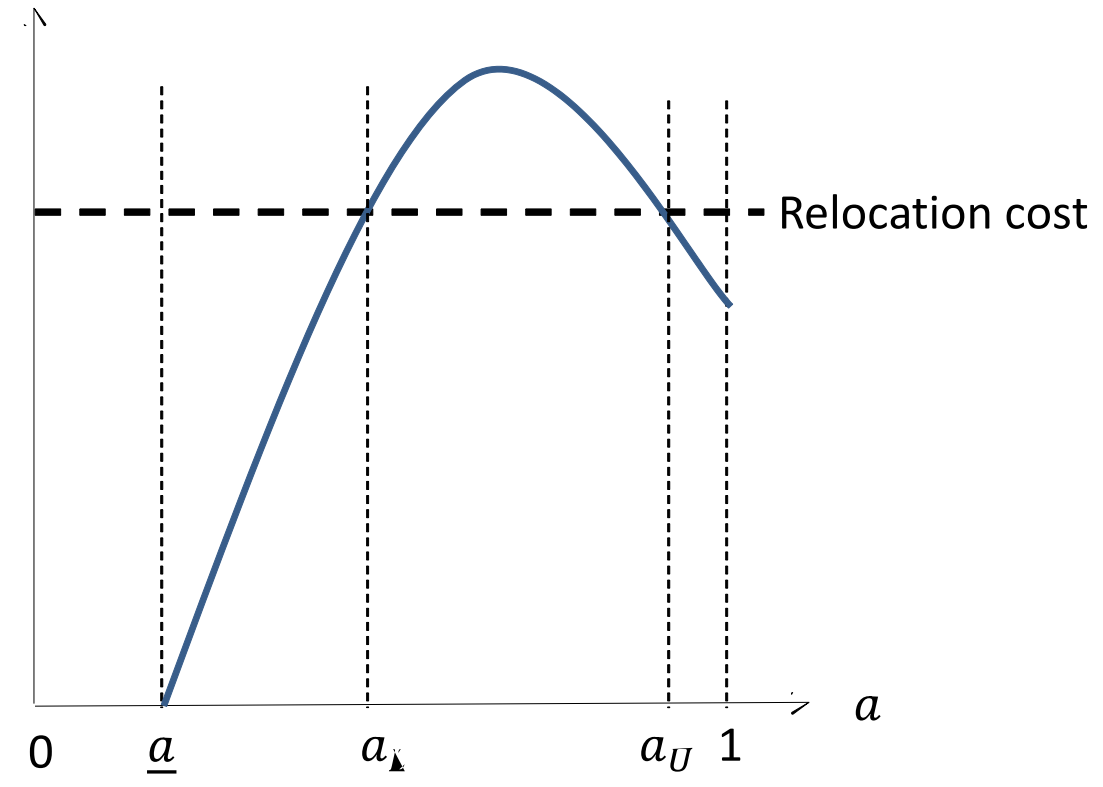

\section{Deviation tendency (initial eq)}

Figure 3: The generic case of intermediate scale economies in transportation $\left(\gamma<\frac{1}{\varphi}-1\right)$.

Firms move as long as the profit gap is larger than the relocation cost, and the long-run equilibrium is therefore defined by:

$$
\pi_{j}\left(a_{i}\right)-\pi_{k}\left(a_{i}\right)=\frac{\mu}{(\sigma-\mu)}\left(1-\varphi a_{i}^{\gamma(1-\sigma)}\right) a_{i}^{1-\sigma}\left(\frac{s_{j}}{\Delta_{j}}-\frac{1-s_{j}}{\Delta_{k}}\right)=0
$$

The first thing to note, from (15), is that the profit differential is zero for $a=\underline{a} \equiv t^{-\frac{1}{\gamma}}$. This implies that $a_{L}=\underline{a} \equiv t^{-\frac{1}{\gamma}}$ in a long-run equilibrium. $a_{U}$ must also be solved. The long-run equilibrium value of $a_{U}$ is defined by:

$$
\pi_{j}\left(a_{U}\right)-\pi_{k}\left(a_{U}\right)=\frac{\mu}{(\sigma-\mu)}\left(1-\varphi a_{U}^{\gamma(1-\sigma)}\right) a_{U}^{1-\sigma}\left(\frac{s_{j}}{\Delta_{j}}-\frac{1-s_{j}}{\Delta_{k}}\right)=0
$$

where

$$
\begin{aligned}
\Delta_{j}\left(a_{R}\right) & \equiv s_{j} \int_{a}^{1} a^{1-\sigma} d F(a)+\phi\left(1-s_{j}\right) \int_{a}^{1} a^{1-\sigma} d F(a)+\left(1-s_{j}\right)(1-\phi) \int_{a_{L}}^{a_{U}} a^{1-\sigma} d F(a),(17 \\
\Delta_{k}\left(a_{R}\right) & \equiv\left(1-s_{j}\right) \int_{a_{R}}^{1} a^{1-\sigma} d F(a)+\phi s_{j} \int_{a}^{1} a^{1-\sigma} d F(a)+\left(1-s_{j}\right)(\phi-1) \int_{a_{L}}^{a_{U}} a^{1-\sigma} d F(a) .(18)
\end{aligned}
$$

Solving (17) and (18) gives 


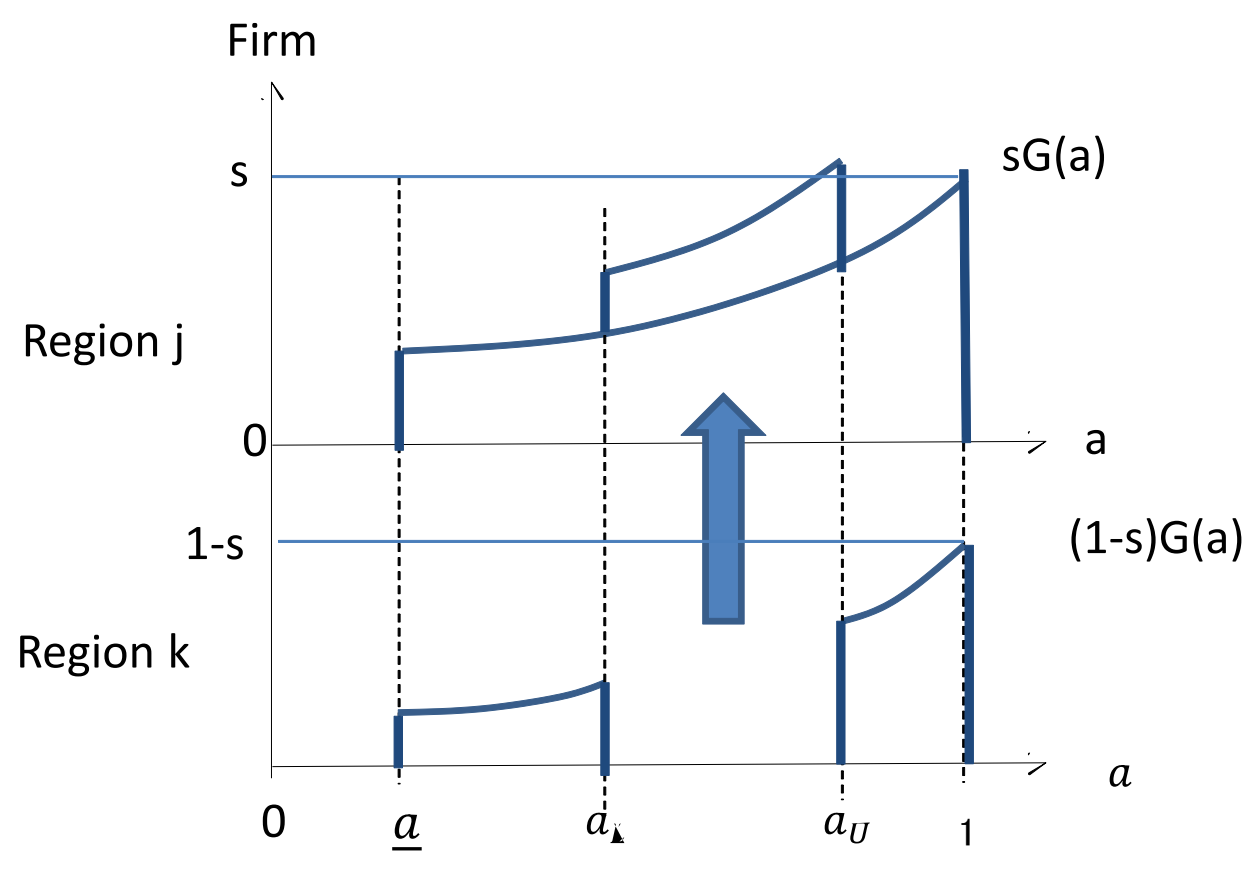

Figure 4: The relocation pattern with two cut-offs.

$$
\begin{aligned}
\Delta_{j} & =\lambda\left\{s\left(1-\underline{a}^{\beta}\right)+(1-s)\left(a_{U}^{\beta}-a_{L}^{\beta}\right)\right\}+\theta \varphi\left\{(1-s)\left(a_{L}^{\alpha}-\underline{a}^{\alpha}\right)+(1-s)\left(1-a_{U}^{\alpha}\right)\right\} \\
\Delta_{k} & =\theta \varphi\left\{s\left(1-\underline{a}^{\alpha}\right)+(1-s)\left(a_{U}^{\alpha}-a_{L}^{\alpha}\right)\right\}+\lambda\left\{(1-s)\left(a_{L}^{\beta}-\underline{a}^{\beta}\right)+(1-s)\left(1-a_{U}^{\beta}\right)\right\}
\end{aligned}
$$

where $\alpha \equiv(\gamma+1)(1-\sigma)+\rho, \beta \equiv 1-\sigma+\rho, \lambda \equiv \frac{\rho}{\beta} \frac{1}{a_{0}^{\rho}-\underline{a}^{\rho}}$, and $\theta \equiv \frac{\rho}{\alpha} \frac{1}{a_{0}^{\rho}-\underline{a}^{\rho}}$. Note that $\alpha<\beta$ (since $\sigma>1$ ) and thus $\lambda<\theta$. Moreover, we note that $\beta \bar{\lambda}=\alpha \theta$.

The relevant solution for $a_{U}$ is determined by $\frac{s}{\Delta_{j}}-\frac{1-s}{\Delta_{k}}=0$. Manipulation gives the following condition that determines the upper cut-off, $a_{U}$ :

$$
\frac{\alpha}{\beta} a_{U}^{\beta}-\varphi a_{U}^{\alpha}=\frac{\alpha}{\beta} t^{-\frac{\beta}{\gamma}}-\varphi \frac{s}{1-s} t^{-\frac{\alpha}{\gamma}}-\varphi\left(1-\frac{s}{1-s}\right)=0
$$

This condition cannot be solved analytically in general but we can use it to derive comparative statistics on $a_{U}$, as seen below. We next turn to the effect of trade liberalisation.

\subsection{Trade liberalisation}

Although we cannot derive a closed form solution for the cut-off, we can investigate the impact of trade liberalisation, i.e. the impact of an increase in $\varphi$ on the cut-off, by implicit differentiation. Using that $\varphi=t^{1-\sigma}$ in $(21)$ gives

$$
F \equiv \frac{\alpha}{\beta} a_{U}^{\beta}-\varphi a_{U}^{\alpha}=\frac{\alpha}{\beta} \varphi^{k \beta}-\varphi^{1-k \alpha} \frac{s}{1-s}-\varphi\left(1-\frac{s}{1-s}\right)=0
$$

where $k \equiv \frac{1}{\gamma(\sigma-1)}$. 


\section{Profit gap}

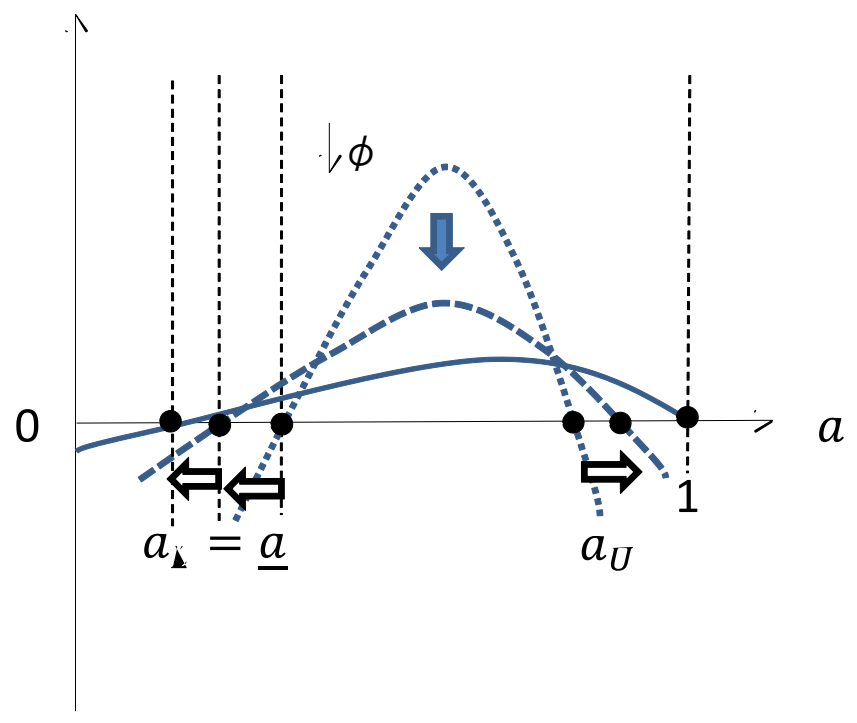

Figure 5: The effect of trade liberalisation

First

$$
\frac{d F}{d a_{U}}=\frac{\alpha}{\beta} \beta a_{U}^{\beta-1}-\varphi \alpha a_{U}^{\alpha-1}=\alpha a_{U}^{\beta-1}-\varphi \alpha a_{U}^{\alpha-1}>0
$$

since $\beta>\alpha$ and $\varphi<1$.

Next

$$
\frac{d F}{d \varphi}=-a_{U}^{\alpha}-\alpha k \varphi^{k \beta-1}+(1-k \alpha) \varphi^{-k \alpha} \frac{s}{1-s}+\frac{1-2 s}{1-s}
$$

All terms on the right-hand side of this expression are negative assuming that $k \alpha>1$. This condition may be rewritten as $\gamma<\frac{\sigma-1}{\rho-\sigma+1}$, where we have used that $\alpha \equiv(1+\gamma)(1-\sigma)+\rho$. We assume this to hold, which implies that

$$
\frac{d F}{d \varphi}<0
$$

Finally, using the implicit function theorem

$$
\frac{d a_{U}}{d \varphi}=-\frac{\frac{d F}{d \varphi}}{\frac{d F}{d a_{U}}}>0 .
$$

Thus, we have shown that, as the trade costs fall, more firms move from Region $k$ to Region $j$ leaving a smaller and smaller set of very high productivity firms in the periphery:

Proposition 2 Trade liberalisation always promotes firm relocation from small to large regions. The most productive firms are the last movers.

The effect of trade liberalisation is illustrated by Figure 5 . 


\subsection{Welfare impact of Trade liberalisation}

Using the Cobb-Douglas utility function, social welfare in our model in Region $j$ and Region $k$ is given by $U_{j}=\frac{s}{\Delta_{j}^{\mu /(1-\sigma)}}$ and $U_{k}=\frac{1-s}{\Delta_{k}^{\mu /(1-\sigma)}}$. Our central interest is $\Delta_{j}$ and $\Delta_{k}$. First, as shown in Appendix 5.1

$$
\frac{d \Delta_{j}}{d \varphi}=\frac{d \Delta_{j}}{d a_{U}} \frac{d a_{U}}{d \varphi}+\frac{d \Delta_{j}}{d a_{L}} \frac{d a_{L}}{d \varphi}+\frac{d \Delta_{j}}{d \varphi}>0
$$

Thus, firm relocation improves social welfare in Region $j$. Then, the same investigation is conducted for Region $k$. The welfare effects are ambiguous in this case (see Appendix 5.1).

$$
\frac{d \Delta_{k}}{d \varphi}=\frac{d \Delta_{k}}{d a_{U}} \frac{d a_{U}}{d \varphi}+\frac{d \Delta_{k}}{d a_{L}} \frac{d a_{L}}{d \varphi}+\frac{d \Delta_{k}}{d \varphi} \lessgtr 0
$$

The indirect effect is always negative, i.e. $\frac{d \Delta_{k}}{d a_{U}} \frac{d a_{U}}{d \varphi}+\frac{d \Delta_{k}}{d a_{L}} \frac{d a_{L}}{d \varphi}<0$, whereas the direct effect is always positive $\frac{d \Delta_{k}}{d \varphi}>0$. This indicates that if trade liberalisation does not relocate firms to any large extent, i.e. because of large relocation costs, welfare is likely to rise. For low relocation costs, the opposite case is likely to occur.

Proposition 3 Trade liberalisation always improves welfare in the large region, while the welfare effect is ambiguous for the small region.

\section{Conclusion}

This paper introduces scale economies in transportation in a trade and geography model with heterogeneous firms. This relatively small change to the standard set-up has large effects on the location pattern of firms. The seminal model by Baldwin and Okubo (2006), as well as other models in this vein, predicts that the most productive firms will sort themselves to the core region. Our paper overturns this result. Firms of intermediate productivity typically sort themselves to the core, whereas high and low productivity firms remain in the periphery. The result of Baldwin and Okubo (2006) only applies when the scale economies in transportation are very low.

We show how trade liberalisation accentuates the sorting, gradually leaving only the most productive firms in the periphery. We also show that, whereas the central region gains from trade liberalisation, the periphery may lose.

An implication of our results is that the spatial sorting of firms in a sector will depend on the degree of scale economies in transportation in that sector. This has several policy implications. Suppose e.g. that the government prompts an industry to change from road transport to trains for environmental reasons. According to our model, this will affect the spatial sorting of the industry, if road transport and trains have different degrees of scale economies. If scale economies in transportation are more pronounced when it comes to rail transports, the large and most productive firms have less of an incentive to move to the core after switching to rail 
transport. This implies a larger number of large firms in the periphery and thus, a geographically more dispersed production. However, this tends to lead to more transportation, which may be detrimental to the environment. Thus, our paper points out a new general equilibrium effect that may be relevant for several policies directed towards the transportation sector.

The trade and geography literature with homogenous firms shows how the agglomeration pattern of a sector depends on the level of transport costs. The introduction of heterogeneous firms implies that it is possible to analyse which firms agglomerate; that is, it is possible to analyse the spatial sorting of firms. Our paper adds to this literature by showing that scale economies of transportation can have an important effect on the spatial sorting of a sector. 


\section{Appendix}

\subsection{Appendix. Welfare effects of trade liberalisation}

First we show that

$$
\frac{d \Delta_{j}}{d \varphi}=\frac{d \Delta_{j}}{d a_{U}} \frac{d a_{U}}{d \varphi}+\frac{d \Delta_{j}}{d a_{L}} \frac{d a_{L}}{d \varphi}+\frac{d \Delta_{j}}{d \varphi}>0
$$

From (17) (18)

$$
\begin{aligned}
\frac{d \Delta_{j}}{d a_{U}} & =(1-s) \lambda \beta a_{U}^{\beta-1}-\varphi(1-s) \alpha \theta a_{U}^{\alpha-1}>0 \\
\frac{d \Delta_{j}}{d a_{L}} & =-(1-s) \lambda \beta a_{L}^{\beta-1}+\varphi(1-s) \alpha \theta a_{L}^{\alpha-1}<0 \\
\frac{d \Delta_{j}}{d \varphi} & =\theta\left\{(1-s)\left(a_{L}^{\alpha}-\underline{a}^{\alpha}\right)+(1-s)\left(1-a_{U}^{\alpha}\right)\right\}>0
\end{aligned}
$$

since $\beta>\alpha, \beta \lambda=\alpha \theta$ and $\varphi<1$. From (26) and since $a_{L}=t^{1-\sigma}$, in the long-run equilibrium we have

$$
\begin{aligned}
\frac{d a_{U}}{d \varphi}>0 \\
\frac{d a_{L}}{d \varphi}<0 .
\end{aligned}
$$

Together these derivatives imply that $\frac{d \Delta_{j}}{d \varphi}>0$.

Next, we illustrate that

$$
\frac{d \Delta_{k}}{d \varphi}=\frac{d \Delta_{k}}{d a_{U}} \frac{d a_{U}}{d \varphi}+\frac{d \Delta_{k}}{d a_{L}} \frac{d a_{L}}{d \varphi}+\frac{d \Delta_{k}}{d \varphi} \lessgtr 0
$$

From (17) (18)

$$
\begin{aligned}
& \frac{d \Delta_{k}}{d a_{U}}=\varphi(1-s) \alpha \theta a_{U}^{\alpha-1}-(1-s) \lambda \beta a_{U}^{\beta-1}<0 \\
& \frac{d \Delta_{k}}{d a_{L}}=-\varphi(1-s) \alpha \theta a_{L}^{\alpha-1}+(1-s) \lambda \beta a_{L}^{\beta-1}>0 \\
& \frac{d \Delta_{k}}{d \varphi}=\theta\left\{s\left(1-\underline{a}^{\alpha}\right)+(1-s)\left(a_{U}^{\alpha}-a_{L}^{\alpha}\right)\right\}>0
\end{aligned}
$$

since $\beta>\alpha, \beta \lambda=\alpha \theta$ and $\varphi<1$ and from (32) and (33), we have $\frac{d a_{U}}{d \varphi}>0$ and $\frac{d a_{L}}{d \varphi}<0$. Together, these derivatives imply that the indirect effect is always negative, i.e. $\frac{d \Delta_{k}}{d a_{U}} \frac{d a_{U}}{d \varphi}+\frac{d \Delta_{k}}{d a_{L}} \frac{d a_{L}}{d \varphi}<0$, whereas the direct effect is positive, $\frac{d \Delta_{k}}{d \varphi}>0$. 


\section{References}

[1] Anderson, J. and E. van Wincoop, (2004). "Trade Costs", Journal of Economic Literature, Vol. XLII: 691-751.

[2] Baldwin, R. and R. Forslid, P. Martin, G. Ottaviano and F. Robert-Nicoud (2003) Economic Geography and Public Policy, Princeton University Press, Princeton.

[3] Baldwin, R.E., and Okubo, T. (2006). Heterogeneous firms, agglomeration and economic geography: spatial selection and sorting. Journal of Economic Geography, 6, pp.323-346.

[4] Behrens, K. and P.M. Picard, (2011). "Transportation, freight rates, and economic geography", Journal of International Economics, vol. 85(2): 280-291.

[5] Behrens, K., C. Gaigné, G.I.P. Ottaviano and J.-F. Thisse (2006). "How density economics in international transportation link the internal geography of trading partners, Journal of Urban Economics, vol 60: 248-263.

[6] Forslid, R and T.Okubo (2012) "On the Development Strategy of Countries of Intermediate Size-An Analysis of Heterogeneous Firms in a Multi-region Framework", European Economic Review 56, pp.747-756.

[7] Fujita, M., P. Krugman, A.J. Venables (1999), The Spatial Economy: Cities, Regions, and International Trade, Cambridge, Mass.: MIT Press.

[8] Fujita, M and J-F Thisse (2002) Economics of Agglomeration, Oxford University Press.

[9] Hummels, D. (1999). "Transport and International Trade", Report of the one hundred and thirtieth round table on transport economics, OECD.

[10] Hummels, D. and A. Skiba, (2004). "Shipping the Good Apples Out: An Empirical Confirmation of the Alchian-Allen Conjecture" Journal of Political Economy 112: 1384-1402.

[11] Hummels, D. (2007). "Transportation Costs and International Trade in the Second Era of Globalization," Journal of Economic Perspectives, vol. 21(3), pages 131-154.

[12] Martin, P. and C.A. Rogers (1995) "Industrial location and public infrastructure," Journal of International Economics 39, 335-351.

[13] McCann, P. (2005). "Transport costs and new economic geography," Journal of Economic Geography, vol. 5(3), pages 305-318.

[14] Melitz, M. J. (2003). "The Impact of Trade on Intra-Industry Reallocations and Aggregate Industry Productivity", Econometrica, 71(6): 1695-1725.

[15] Melitz, M.J. and G.I.P.Ottaviano, (2007). "Market Size, Trade, and Productivity", Review of Economic Studies, 75 (1): 295-316. 
[16] Mori, T., Nishikimi, K.(2002). "Economies of transport density and industrial agglomeration," Regional Science and Urban Economics 32, 167-200.

[17] Okubo, T. Picard, P.M and Thisse, J-F (2010). "The spatial selection of heterogeneous firms", Journal of International Economics 82(2), pp.230-237.

[18] Okubo, T (2009). Trade Liberalisation and Agglomeration with Firm Heterogeneity Forward and Backward Linkages. Regional Science and Urban Economics 39 (5), pp.530541.

[19] Ottaviano, G., T. Tabuchi and J.-F. Thisse (2002) "Agglomeration and Trade Revisited," International Economic Review, Vol. 43, pp. 409-436.

[20] Picard, P.M. and Okubo, T (2012) "Firms Locations under Demand Heterogeneity", Regional Science and Urban Economics 42(6), pp.961-974.

[21] Saito, H., M. Gopinath and J.J. Wu (2011), Heterogeneous rms, trade liberalization and agglomeration, Canadian Journal of Economics 44, 541-560. 